\title{
Toward real-time measurement of atmospheric mercury concentrations using cavity ring-down spectroscopy
}

\author{
X. Faïn, H. Moosmüller, and D. Obrist \\ Division of Atmospheric Sciences, Desert Research Institute, 2215 Raggio Parkway, Reno, NV 89512, USA \\ Received: 2 October 2009 - Published in Atmos. Chem. Phys. Discuss.: 21 October 2009 \\ Revised: 25 February 2010 - Accepted: 26 February 2010 - Published: 26 March 2010
}

\begin{abstract}
Cavity ring-down spectroscopy (CRDS) is a direct absorption technique that utilizes path lengths up to multiple kilometers in a compact absorption cell and has a significantly higher sensitivity than conventional absorption spectroscopy. This tool opens new prospects for study of gaseous elemental mercury $\left(\mathrm{Hg}^{0}\right)$ because of its high temporal resolution and reduced sample volume requirements $(<0.51$ of sample air). We developed a new sensor based on CRDS for measurement of $\left(\mathrm{Hg}^{0}\right)$ mass concentration. Sensor characteristics include sub-ng $\mathrm{m}^{-3}$ detection limit and high temporal resolution using a frequency-doubled, tuneable dye laser emitting pulses at $\sim 253.65 \mathrm{~nm}$ with a pulse repetition frequency of $50 \mathrm{~Hz}$. The dye laser incorporates a unique piezo element attached to its tuning grating allowing it to tune the laser on and off the $\mathrm{Hg}^{0}$ absorption line on a pulse-to-pulse basis to facilitate differential absorption measurements. $\mathrm{Hg}^{0}$ absorption measurements with this CRDS laboratory prototype are highly linearly related to $\mathrm{Hg}^{0}$ concentrations determined by a Tekran $2537 \mathrm{~B}$ analyzer over an $\mathrm{Hg}^{0}$ concentration range from $0.2 \mathrm{ng} \mathrm{m}^{-3}$ to $573 \mathrm{ng} \mathrm{m}^{-3}$, implying excellent linearity of both instruments. The current CRDS instrument has a sensitivity of $0.10 \mathrm{ng} \mathrm{Hg}^{0} \mathrm{~m}^{-3}$ at 10 -s time resolution. Ambient-air tests showed that background $\mathrm{Hg}^{0}$ levels can be detected at low temporal resolution (i.e., $1 \mathrm{~s}$ ), but also highlight a need for high-frequency (i.e., pulse-to-pulse) differential on/off-line tuning of the laser wavelength to account for instabilities of the CRDS system and variable background absorption interferences. Future applications may include ambient $\mathrm{Hg}^{0}$ flux measurements with eddy covariance techniques, which require measurements of $\mathrm{Hg}^{0}$ concentrations with sub-ng $\mathrm{m}^{-3}$ sensitivity and sub-second time resolution.
\end{abstract}

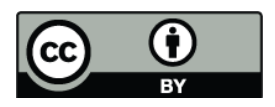

Correspondence to: X. Faïn (xavier.fain@dri.edu)

\section{Introduction}

Mercury $(\mathrm{Hg})$ is a toxic pollutant globally dispersed in the environment. Natural and anthropogenic sources emit mercury to the atmosphere, either as gaseous elemental mercury $\left(\mathrm{GEM}\right.$ or $\mathrm{Hg}^{0}$ ) or as divalent mercury species. $\mathrm{Hg}^{0}$ represents as much as $95 \%$ of the atmospheric mercury burden and can be transported across long distances to remote locations. Many aspects of mercury chemical cycling in the atmosphere are still essentially unknown, and estimates of $\mathrm{Hg}^{0}$ atmospheric lifetime range from 5 to 24 months (Schroeder and Munthe, 1998). Measurements of atmospheric background levels of $\mathrm{Hg}^{0}\left(\sim 1.7 \mathrm{ng} \mathrm{m}^{-3}\right.$ in the Northern Hemisphere; Valente et al., 2007) currently require preconcentration of $\mathrm{Hg}^{0}$ from several liters of air using gold amalgamation for a duration of several minutes, followed by thermal dissociation of collected $\mathrm{Hg}^{0}$ for measurements and analysis by atomic fluorescence or absorption spectroscopy (e.g., Model 2537B, Tekran Inc., Toronto, Canada; typical time resolution of 2.5 to $5 \mathrm{~min}$ ). Laser-induced fluorescence (LIF) has been developed as a promising alternative technique for detection of mercury in laboratory studies with a detection limit of $0.4 \mathrm{ng} \mathrm{m}^{-3}$ for a $1 \mathrm{~s}$ integration (Bauer et al., 2003). The analyzer Lumex RA-915+ (Lumex Ltd., Ohio, USA) is a commercially available unit based on the absorption of $\mathrm{Hg}^{0}$ atom resonance radiation with Zeeman correction for background absorption which allows for $\mathrm{Hg}^{0}$ sampling at $1 \mathrm{~Hz}$ frequency. The detection limit of Lumex analyzer, however, remains poorly elucidated. Comparative analysis made between a Lumex system and a traditional CVAAS method (WA-4 model, Nippon Instrument Corp., NIC, Japan) demonstrated that both systems could exhibit a good compatibility even in the low concentration ranges (Kim et al., 2006). In the manufacturer's performance report made as continuous vehicular survey (http:// www.ohiolumex.com/download/03AE07011.pdf), the detection limit values of the system were shown to vary sensitively from 0.3 to $2.0 \mathrm{ng} \mathrm{m}^{-3}$.

Published by Copernicus Publications on behalf of the European Geosciences Union. 

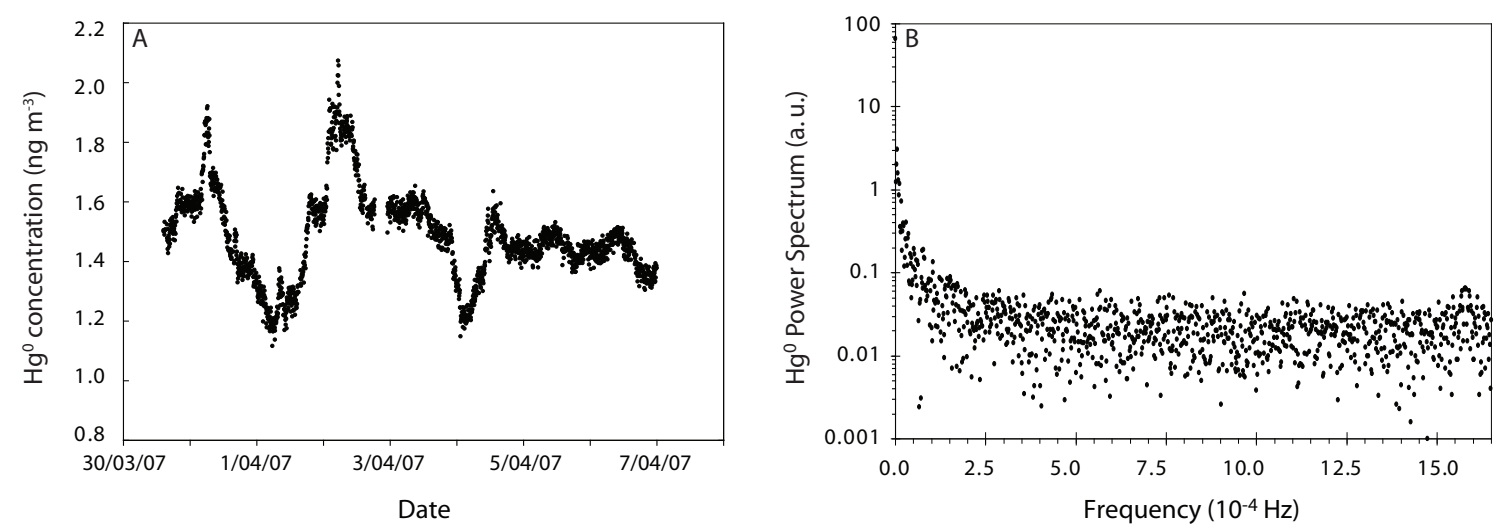

Fig. 1. A High levels of gaseous elemental mercury measured as a function of time with a Tekran 2537B analyzer at Storm Peak Laboratory (3200 m a.s.1.) in the US Rocky Mountains and attributed to long-range transport of pollutants from Asian sources. B Corresponding power spectral density as a function of frequency for $\mathrm{Hg}^{0}$ concentrations.

Our current understanding of mercury dynamics in the atmosphere and surface exchange processes is hindered by the low time resolution of mercury sensors leading to substantial uncertainties in global atmospheric mercury cycling. High-frequency $\mathrm{Hg}^{0}$ concentration fluctuations likely are occurring at sampling intervals $(\Delta)$ shorter than the 2.5min resolution of current technology and may portray inaccurately important information about atmospheric sources, sinks, and chemical transformation processes. An example of 5-min time resolution measurements of $\mathrm{Hg}^{0}$ at the Desert Research Institute's (DRI's) high elevation research facility (Storm Peak Laboratory, $3200 \mathrm{~m}$ a.s.l.) in the US Rocky Mountains (Fig. 1a) shows $\mathrm{Hg}^{0}$ concentration enhancement attributed to long-range transport of pollutants from Asian sources (Obrist et al., 2008). We used Fourier spectral techniques to obtain the power spectral density of this data series in frequency space. The resulting power spectrum is shown in Fig. $1 b$ as a function of frequency, which ranges from $0 \mathrm{~Hz}$ to the Nyquist frequency, $1 /(2 \Delta)=1 /(10 \mathrm{~min})=1.67 \times 10^{-3} \mathrm{~Hz}$, which is the highest frequency at which information can be obtained. Figure $1 \mathrm{~b}$ shows that there is no significant drop off of the power spectral density toward the Nyquist frequency, and we expect (but are not able to quantify) significant contributions above the Nyquist frequency. In other words, temporal changes in $\mathrm{Hg}^{0}$ concentrations faster than the current 5-min time resolution are likely to occur at a significant level and may contain important information about $\mathrm{Hg}^{0}$ fluctuations which are not measureable with current sensors. A fast-response sensor will lead to major progress in air mass characterization, such as in the study mentioned above (Obrist et al., 2008). Other potential applications include quantification of $\mathrm{Hg}^{0}$ emission and deposition fluxes with micrometeorological techniques (e.g., Eddy Covariance) that require high measurement frequencies (e.g., 1 to $10 \mathrm{~Hz}$ ), characterization of in situ and laboratory chemical and physical transformation pathways of mercury (i.e., tropospheric oxidation of $\mathrm{Hg}^{0}$ ), and characterization of global transport patterns and atmospheric mercury residence notably by spatially resolved airborne measurements.

Gaseous elemental mercury is a unique atmospheric pollutant that occurs in the form of individual mercury atoms in contrast to virtually all other atmospheric pollutants that occur in molecular form. As a consequence, the transition strength of $\mathrm{Hg}^{0}$ absorption lines is concentrated in individual, narrow lines not split into a multitude of vibrational-rotational lines, and therefore $\mathrm{Hg}^{0}$ absorption lines are much stronger than the usual molecular absorption lines. Absorption measurements are a promising approach to measuring mercury concentrations. Cavity ring-down spectroscopy (CRDS), a sensitive absorption measurement method, which employs very long absorption path lengths in compact cavities (e.g., Berden et al., 2000), is especially well suited to detecting atmospheric $\mathrm{Hg}^{0}$ concentrations and fluxes. CRDS was investigated previously for detection of $\mathrm{Hg}^{0}$ concentrations, although detection limits were too high for most ambient air applications (see Sect. 2.4). In this paper, we report advances in development of a new laboratory prototype CRD spectrometer, demonstrating a sensitivity of $0.10 \mathrm{ng} \mathrm{m}^{-3}$ at a time resolution of $10 \mathrm{~s}$ which makes this technique an interesting alternative for use in ambient air, background concentration studies. We also report detailed comparison of CRDS $\mathrm{Hg}^{0}$ absorption measurements with data from the existing Tekran 2537B analyzer both using laboratory-supplied $\mathrm{Hg}^{0}$ concentrations and ambient air, and discuss the utility of our CRDS $\mathrm{Hg}^{0}$ instrument for use in laboratory and field studies. 


\section{Theory of absorption spectroscopy and cavity ring-down detection}

\subsection{Theory of mercury absorption spectroscopy}

Of particular interest for the sensitive detection of $\mathrm{Hg}^{0}$ with absorption spectroscopy is the $6 \mathrm{~s}^{1} \mathrm{~S}_{0} \rightarrow 6 \mathrm{p}^{3} \mathrm{P}_{1}$ electronic transition from the $6 \mathrm{~s}$ ground state, to the $6 \mathrm{p}$ excited state. An absorption cross section of $3.3 \times 10^{-14} \mathrm{~cm}^{2}$ atom ${ }^{-1}$ has been reported for this $\mathrm{Hg}^{0}$ absorption line at $253.65 \mathrm{~nm}$ in the ultraviolet (UV) (Edner et al., 1989; Spuler et al., 2000). This line has an approximate full width at half-maximum (FWHM) of $0.005 \mathrm{~nm}$ at atmospheric pressure, due to hyperfine splitting and atmospheric pressure broadening resulting in a single peak containing all hyperfine components. The high-resolution structure of the $\mathrm{Hg}^{0}$ absorption spectrum is dominated by hyperfine splitting due to interactions of the nuclear multipole moments of the seven (five with even and two with odd nuclei numbers) naturally occurring isotopes with their electrons.

Direct absorption spectroscopy of atoms and molecules in the gas phase is a powerful tool that can yield absolute concentration measurements. According to Beer's law, the transmittance of light through a path length $L(\mathrm{~m})$ of an absorbing medium is given by:

$T(\nu)=P / P_{\mathrm{O}}=\exp (-\alpha(\nu) \cdot L)$

where $P_{\mathrm{O}}$ is the optical power before the absorber $(\mathrm{W}), P$ is the optical power after the absorber $(\mathrm{W})$, and $\alpha(v)$ is the absorption coefficient $\left(\mathrm{m}^{-1}\right)$ at the frequency $v$. The absorption is then given by:

$A(v)=1-T(v)$

The absorption lineshape $A(v)$ of $\mathrm{Hg}^{0}$ for a given temperature and pressure can be modeled with a Voigt profile, which is a convolution of Gaussian and Lorentzian components. Detailed theoretical descriptions are available elsewhere (e.g., Anderson et al., 2007; Finkelstein, 1998). Briefly, the Gaussian, or inhomogeneous component, is due to Doppler broadening with a line width proportional to the square root of the ratio of temperature and atomic weight of mercury. The Lorentzian profile is the homogenous component due to natural lifetime and pressure broadening. The Lorentzian width is the sum of the width of natural lifetime broadening and collisional broadening (a function of pressure) widths, which have been experimentally determined.

\subsection{Cavity ring-down spectroscopy}

Conventional absorption spectroscopy is based on measurement of the change in the optical power during transmission through an absorbing medium according to Beer's law (Eq. 1). Sensitivity of this method is limited by temporal noise of the light source or incident optical power because a small change in power due to absorption needs to be quantified. Sensitivity can be improved by measuring optical power relative to the incident power and by using a long absorption path, thereby increasing the absorption signal. Cavity ringdown spectroscopy is a simple, fast, and sensitive absorption technique that measures the relative optical power and implements very long absorption paths in compact CRDS absorption cells. The sample is placed inside a high-finesse optical cavity consisting of highly reflective mirrors. A small fraction of a short laser pulse is coupled into the cavity through one of its mirrors; the laser pulse is reflected back and forth inside the cavity with a small fraction of the pulse leaking out of the cavity at every reflection due to residual mirror transmission. If the laser pulse is shorter than the cavity's roundtrip length, no interference occurs.

Optical energy stored in the cavity decays exponentially with time due to extinction between the mirrors and reflection losses at the mirrors (O'Keefe and Deacon, 1988; Ramponi et al., 1988). The power of the light leaking out of the cavity through one of the mirrors is proportional to the optical energy in the cavity, and decay time of the cavity is determined by measuring the optical power leaking out of the cavity as a function of time with a fast detector and fitting an exponential function to it. Note that this technique is in principle not affected by laser noise, defined as pulse-to-pulse fluctuations of laser power.

CRDS obtains total cavity extinction, which is the sum of mirror reflection losses, sample scattering, and sample absorption. Assuming that extinction due to mirror losses and sample scattering are constant, they can be subtracted from the total extinction coefficient, resulting in a calibrated measurement of the absorption coefficient of the sample; the more the sample absorbs, the shorter is the measured decay time. The effective absorption path length depends on reflectivity of the cavity mirrors and can be very long (up to several kilometers), while the sample volume can be kept rather small (Moosmüller et al., 2005).

\subsection{Cavity ring-down signal analysis}

For highly reflecting mirrors, the time-dependent CRDS signal $S(t)$ can be written as

$$
S(t)=S_{0} \exp [-\alpha c t]=S_{0} \exp \left[-\left(\alpha_{\mathrm{Hg}}+\alpha_{\mathrm{BG}}+\alpha_{\mathrm{M}}\right) \cdot c t\right]
$$

where $S_{0}$ is the initial signal (i.e., at $t=0$ ) and $c$ is the speed of light. The total extinction coefficient $\alpha$ is the sum of a strongly wavelength dependent $\mathrm{Hg}^{0}$ absorption coefficient $\alpha_{\mathrm{Hg}}$ and two additional terms: a background extinction term $\alpha_{\mathrm{BG}}$ due to other gaseous and particulate absorption and scattering and a mirror extinction term $\alpha_{\mathrm{M}}$. Both of these additional terms are largely wavelength independent within the small wavelength range (i.e., $\approx 0.01 \mathrm{~nm}$ ) of interest. We can 
estimate the mass concentrations $C_{\mathrm{Hg}}$ of $\mathrm{Hg}^{0}$ from a measurement of the absorption coefficient $\alpha_{\mathrm{Hg}}$ as:

$$
C_{\mathrm{Hg}}=\frac{\alpha_{\mathrm{Hg}} M_{\mathrm{Hg}}}{N_{\mathrm{A}} \sigma_{\mathrm{Hg}}}
$$

where $M_{\mathrm{Hg}}$ is the atomic mass of mercury $\left(200.59 \mathrm{~g} \mathrm{~mol}^{-1}\right)$, $N_{\mathrm{A}}$ is Avogadro's number, and $\sigma_{\mathrm{Hg}}$ is the absorption cross section of $\mathrm{Hg}^{0}$. The mirror extinction term $\alpha_{M}$ is a function of the distance $L$ between the two mirrors and mirror reflectivity $R$ with:

$$
S(t)=S_{0} \cdot \exp [-\alpha c t]=S_{0} \cdot \exp \left[-\left(\alpha_{\mathrm{G}}+\alpha_{\mathrm{BG}}+\alpha_{\mathrm{M}}\right) c t\right]
$$

The effective path length $L_{\text {eff }}$ of this CRD arrangement is given by:

$$
L_{\text {eff }}=\frac{1}{\alpha_{\mathrm{Hg}}+\left(\alpha_{\mathrm{BG}}+\alpha_{\mathrm{M}}\right)}=\frac{L}{\alpha_{\mathrm{Hg}} L+\alpha_{\mathrm{BG}} L+(1-R)}
$$

where for low $\mathrm{Hg}^{0}$ concentrations, $\alpha_{\mathrm{Hg}}$ can be neglected and if particle and gaseous absorption and scattering losses are small, the effective path length $L_{\text {eff }}$ can be estimated as:

$L_{\text {eff }}=\frac{L}{1-R}$

For example, for a mirror reflectivity $R$ of $99.9 \%$ and a mirror distance $L$ of $1 \mathrm{~m}$, an effective path length of up to $1 \mathrm{~km}$ can be achieved with path lengths increasing and detection becoming more sensitive for mirrors with higher reflectivity.

\subsection{Performance of previous cavity ring-down spectrometers for $\mathrm{Hg}^{\mathbf{0}}$ detection}

$\mathrm{Hg}^{0}$ detection with CRDS systems has been demonstrated by previous studies, but the sensitivity and time resolution needed for measurement of ambient $\mathrm{Hg}^{0}$ concentrations and fluxes in the field have not been achieved. Jongma et al. (1995) pioneered ultraviolet CRDS detection of trace gases including $\mathrm{Hg}^{0}$ with a frequency-doubled, pulsed dye laser (linewidth of $0.1 \mathrm{~cm}^{-1}$ ) pumped by a frequency-tripled Nd:YAG laser at $355 \mathrm{~nm}$ and a $0.45 \mathrm{~m}$ length open-path CRDS cavity using mirrors with $99.6 \%$ reflectivity. This setup was used to measure $\mathrm{Hg}^{0}$ background concentrations (i.e., $63 \mathrm{ng} \mathrm{m}^{-3}$ ) in their laboratory with a noise-equivalent ( $1 \sigma$ detection limit of $9 \mathrm{ng} \mathrm{m}^{-3}$ for $3 \mathrm{~s}$ averaging time. In addition, nearby absorption lines were identified as the forbidden oxygen $\left(\mathrm{O}_{2}\right) \mathrm{A} \leftarrow \mathrm{X}(7,0)$ transition $(\mathrm{N} "=19$; $\mathrm{Q}$ multiplet). A similar laser system was used later by Tao et al. (2000) and by Spuler et al. (2000). Tao et al. (2000) reported a noise-equivalent $(3 \sigma)$ detection limit of $24 \mathrm{ng} \mathrm{m}^{-3}$ over an unspecified averaging time with a $0.56 \mathrm{~m}$ length open-path CRD cavity with a $0.18 \mathrm{~m}$ sample length and mirrors of $99.7 \%$ reflectivity. Spuler et al. (2000) achieved a noise-equivalent $(3 \sigma)$ detection limit of $4.5 \mathrm{ng} \mathrm{m}^{-3}$ over $75 \mathrm{~s}$ averaging time with a $1.25 \mathrm{~m}$ length closed-path CRDS cavity and mirrors of $99.85 \%$ reflectivity and demonstrated interference-free (i.e., from ozone and sulfur dioxide) measurement of $\mathrm{Hg}^{0}$ at ambient conditions. More recently, Carter (2004) developed a CRDS system for measurement of $\mathrm{Hg}^{0}$ concentrations in flue gases based on an all solid state, frequency-tripled Alexandrite laser, seeded with a singlemode, external-cavity diode laser, thereby reducing the UV output linewidth from $5 \mathrm{~cm}^{-1}$ to less than $0.006 \mathrm{~cm}^{-1}$. Using a $0.65 \mathrm{~m}$ length closed-path CRDS cavity and mirrors of $99.7 \%$ reflectivity, a sensitivity of $90 \mathrm{ng} \mathrm{m}^{-3}$ was achieved over an averaging time of $10 \mathrm{~s}$. Development of alternative plasma sources for CRDS measurement of $\mathrm{Hg}^{0}$ was reported by Duan et al. (2005) using a dye laser system similar to that of Jongma et al. (1995) and an open-path CRDS cavity with mirrors of $99.72 \%$ reflectivity. Their detection limit was $400 \mathrm{ng} \mathrm{m}^{-3}$ for an average time of $5 \mathrm{~s}$. Finally, Wang et al. (2005) used a similar system with a $0.78 \mathrm{~m}$ length openpath CRDS cavity with mirrors of $99.67 \%$ reflectivity and a plasma source filling a $6 \mathrm{~mm}$ length of the CRDS cavity with $\mathrm{Hg}^{0}$. They obtained a noise-equivalent $(3 \sigma)$ detection limit of $2 \mu \mathrm{g} \mathrm{m}^{-3}$ over an averaging time of $2-5 \mathrm{~s}$. Table 1 summarizes detection limits extrapolated to $1 \mathrm{~Hz}$ of previous cavity ring-down spectrometers. Table 1 also includes comparison with commercially available $\mathrm{Hg}^{0}$ analyzers, such as Tekran 2537B and Lumex RA 915+.

\section{Instrument description and laboratory and ambient air testing}

\subsection{Laser and optics}

Figure 2 is a schematic diagram of our CRDS instrument. This instrument uses a frequency-doubled tunable dye laser emitting pulses at a wavelength of $253.65 \mathrm{~nm}$ with a linewidth of $\sim 0.9 \mathrm{GHz}$ and a pulse repetition frequency of $50 \mathrm{~Hz}$. The dye laser system (Newport-Spectra-Physics, Mountain View, CA) consists of a Quanta Ray, Q-switched, frequently-tripled Nd:YAG laser operating at a fundamental wavelength of $1064 \mathrm{~nm}$ with $50 \mathrm{~Hz}$ pulse repetition frequency and generating output pulses at $355 \mathrm{~nm}$ after 3rd harmonic frequency conversion. The $355 \mathrm{~nm}$ pulses are used to pump a dye laser (Model Sirah Cobra) to generate laser pulses at $253.65 \mathrm{~nm}$ after frequency doubling. Average UV dye laser power is $\sim 10 \mathrm{~mW}$ corresponding to a pulse energy of $200 \mu \mathrm{J} / \mathrm{pulse}$. The dye laser wavelength is tunable over a wide range (215-280 nm) using computer-controlled Littrow grating in the dye resonator.

The laser beam is mode-matched with an appropriate lens into a $1 \mathrm{~m}$ length optical cavity consisting of two highly reflecting plano-concave mirrors. The sample is enclosed in the CRDS cavity by a quartz $\left(\mathrm{SiO}_{2}\right)$-coated stainless steel tube that shows no contamination or memory-effect for $\mathrm{Hg}^{0}$ when flushed upstream with a mercury-free air generator (Tekran unit 1100) and monitored downstream with a 2537B Tekran analyzer (see Sect. 3.4 for more details on analyzer 2537B). 
Table 1. Overview of detection limits extrapolated to $1 \mathrm{~Hz}$ for $\mathrm{Hg}^{0}$, including previous cavity ring-down and laser-induced fluorescence spectrometers, Tekran 2537B and Lumex RA-915+ analyzers, and our prototype.

\begin{tabular}{lc}
\hline Instruments and references & $\begin{array}{c}\text { Detection limit } \\
\left(\mathrm{ng} \mathrm{m}^{-3} \mathrm{~Hz}^{-1 / 2}\right)\end{array}$ \\
\hline Cavity ring-down spectrometry & 15.6 \\
$\quad$ Jongma et al. (1995) & 39 \\
Spuler et al. (2000) & 285 \\
Carter et al. (2004) & 894 \\
Duan et al. (2005) & 3714 \\
$\quad$ Wang et al. (2005) & 0.31 \\
This study & \\
Laser induced fluorescence spectrometry & 0.4 \\
Bauer et al. (2003) & \\
Cold vapor atomic fluorescence spectrometry & $1.7^{\mathrm{a}}$ \\
2537B, Tekran & \\
Atomic absorption spectrometry & $0.3-2.0^{\mathrm{b}}$ \\
$\quad$ RA-915+, Lumex & \\
\hline
\end{tabular}

${ }^{a}$ Extrapolated from a $0.1 \mathrm{ng} \mathrm{m}^{-3}$ detection limit at a 5-min time resolution.

$\mathrm{b}$ Detection limit range observed by manufacturer during automobile surveys.

The plano-concave UV mirrors (MLD Technologies, Mountain View, CA) have a radius of curvature of $1 \mathrm{~m}$ and are mounted with adjustable, sealed mirror mounts (Los Gatos Inc., Los Gatos, CA) to form a stable optical cavity. Mirror reflectivity was determined to be $99.895 \%$ from CRDS measurements at $253.65 \mathrm{~nm}$ (i.e., the $\mathrm{Hg}^{0}$ absorption line) for a cavity filled with ultrapure $\mathrm{N}_{2}$. In this configuration, absorption due to $\mathrm{N}_{2}$ can be neglected, and total cavity losses are due to mirror reflection losses plus $\mathrm{N}_{2}$ Rayleigh scattering. The $\mathrm{N}_{2}$ scattering coefficient at $253.65 \mathrm{~nm}$ and laboratory temperature and pressure (i.e., $300 \mathrm{~K}, 843 \mathrm{mbar}$, respectively) was estimated as $259.4 \mathrm{Mm}^{-1}$ using values reported by Fröhlich and Shaw (1980).

\subsection{Data acquisition and signal processing}

Optical energy stored in the cavity is monitored by measuring the optical power leaking through the back cavity mirror (Fig. 2) as a function of time with a high-speed photomultiplier tube (PMT) (H6780; Hamamatsu, Japan). Signals are recorded using a $4 \mathrm{MS} \mathrm{s}^{-1}$ data acquisition card (CompuScope 12100, GaGe, Lockport, Illinois, USA) and processed in real time using Labview, a graphical programming environment for instrument control and data acquisition.

\subsection{Laser wavelength control using an external mercury cell}

Repeatable measurements of $\mathrm{Hg}^{0}$ concentration using CRDS require precise control and corrections of potential drifts in the UV dye laser wavelength. Setting the laser wavelength to the peak of the $\mathrm{Hg}^{0} 253.65 \mathrm{~nm}$ absorption line, where most sensitive detection is feasible, was achieved by direct measurement of the absorption signal of $\mathrm{Hg}^{0}$ in a lowpressure $\mathrm{Hg}^{0}$ vapor cell. As shown in Fig. 2, a fused silicate plate (ESCO Corp., Oak Ridge, NJ, USA) located before the CRDS cavity allowed for extraction of a small fraction of the laser power, which was further split into two equal power laser beams using a UV beam splitter (Edmund Optics Inc., Barrington, NJ, USA), and signals were measured using two photodiodes (PD1 and PD2, DET10M, Thorlabs, Newton, NJ, USA). We routed one of the laser beams through a lowpressure $\mathrm{Hg}^{0}$ cell, and its power was measured by PD1 with this PD1 signal normalized by the PD2 signal - a measure of laser power to correct for fluctuations in the UV laser power (Fig. 2). The $\mathrm{Hg}^{0}$ cell consists of a $50 \mathrm{~mm}$ long, $8 \mathrm{~mm}$ diameter, fused silica tube with two fused silica windows attached at $15^{\circ}$ relative to normal to avoid direct back reflections and reduce etalons effects. Liquid mercury was held in a sealed tube extending from the bottom of the cell, and cell $\mathrm{Hg}^{0}$ concentration was controlled through temperature control of the liquid mercury using an ice bath at $273 \mathrm{~K}$, prepared following ASTM standard procedure E563-08 (2008). However, the sealed tube was likely too small to allow for cooling of the liquid mercury down to $273 \mathrm{~K}$, as discussed in Sect. 4.1. The photodiode signals were extracted from background noise through time-windowing using two independent Boxcar amplifiers (Daly et al., 1985; Stanford Research Systems, 2001) before data acquisition with a data acquisition (DAQ) module (National Instruments, Austin, TX, USA). Control of laser drifts was implemented using the hyperfine structure of the mercury absorption line resolved when using a low pressure $\mathrm{Hg}^{0}$ cell (i.e., $1.3 \times 10^{-5} \mathrm{~Pa}$ ). Specifically, real-time monitoring of the laser power incident on photodiodes PD1 and PD2 allowed for (i) manual locking of the laser wavelength to the peak of the absorption line of the ${ }^{202} \mathrm{Hg}$ isotope before each measurement with an estimated precision of $0.0002 \mathrm{~nm}$, and (ii) control of potential drifts of the UV wavelength during CRDS measurements. However, data collection periods in this study were limited to 10 -s time periods (see Sect. 4.2), and laser drift was never observed during these short timescales.

\subsection{Gaseous elemental mercury source permeation and comparison to Tekran Model 2537B mercury analyzer}

To evaluate performance of the CRDS $\mathrm{Hg}^{0}$ absorption measurements, we built an $\mathrm{Hg}^{0}$ vapor generation system to supply a wide range of $\mathrm{Hg}^{0}$ concentrations to the CRDS 


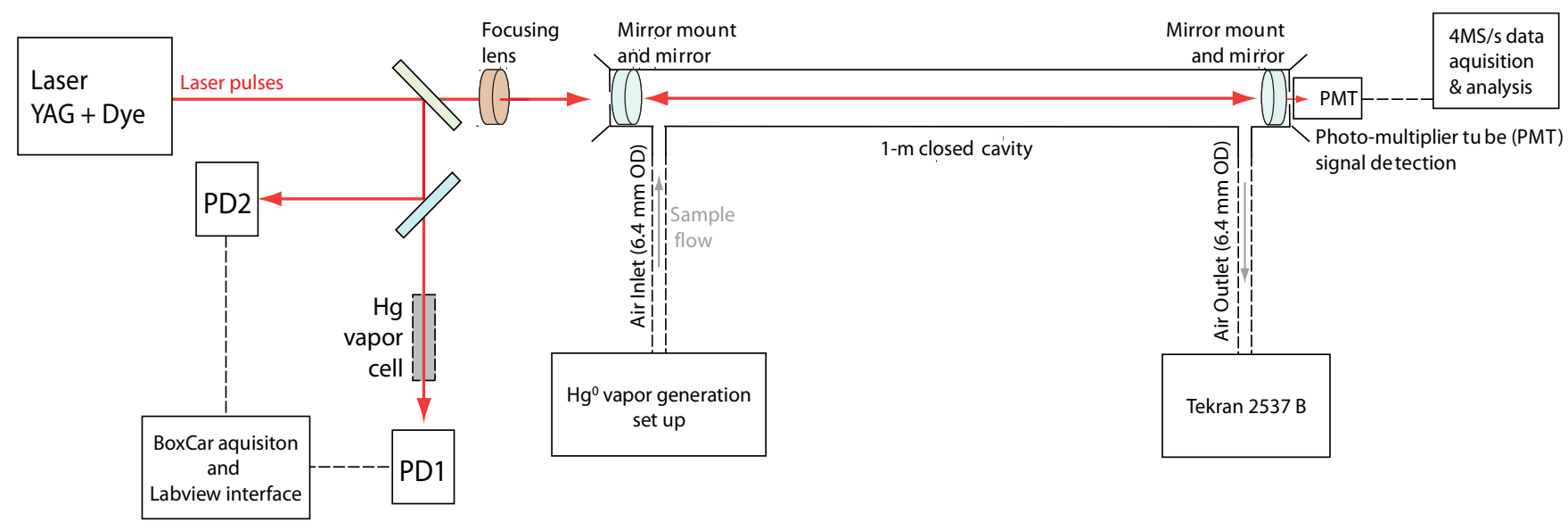

Fig. 2. Schematic overview of CRDS laboratory system.

instrument and used a Tekran Instruments Corp. (Toronto, Canada) Model 2537B analyzer for instrument comparison. We obtained controlled trace concentrations of $\mathrm{Hg}^{0}$ using an HE-SR 1.7CM permeation tube (VICI Metronics, Inc., Poulsbo, WA, USA) with a certified rate of $31.24 \pm \mathrm{ng} \mathrm{\textrm {min } ^ { - 1 }}$ at $50^{\circ} \mathrm{C}$. The permeation tube was kept at constant temperature $\left(50^{\circ} \mathrm{C}\right)$ using a temperature-regulated water bath (Cole Parmer, Vernon Hills, IL, US), and the permeation flow was controlled to adjust the flushing rate above the tube resulting in adjustable source concentrations of $\mathrm{Hg}^{0}$. A small fraction of this primary $\mathrm{Hg}^{0}$ source was diluted with mercury-free air (Air-Zero filter; Model Tekran 30-25150-00) with flows regulated by two mass flow meters (Aalborg, Orangeburg, NY, USA)-one dedicated to the concentrated primary $\mathrm{Hg}^{0}$ source adjustable from $1-10 \mathrm{ml} \mathrm{min}^{-1}$ and one dedicated to the $\mathrm{Hg}^{0}$-free air adjustable from $1.1-101 \mathrm{~min}^{-1}$. This setup allowed for generation of stable $\mathrm{Hg}^{0}$ concentrations through a range from well below $1 \mathrm{ng} \mathrm{m}^{3}$ to $600 \mathrm{ng} \mathrm{m}^{-3}$.

We conducted ambient-air measurements by pulling outside air with background $\mathrm{Hg}^{0}$ concentrations (i.e., ranging from 1.7 to $2.3 \mathrm{ng} \mathrm{m}^{-3}$ ) through a $10 \mathrm{~m}$ Teflon line and a $0.2 \mu \mathrm{m}$ Teflon filter (sampling rate: $1.51 \mathrm{~min}^{-1}$ ), a common air sampling set-up used for Tekran 2537 $\mathrm{Hg}^{0}$ measurements. Ambient air runs included: (i) ambient air with no additional air filtering (i.e., $0.2 \mu \mathrm{m}$ cutoff), (ii) ambient air with an ozone denuder (inserted into the sample stream), (iii) ambient air with an ozone denuder and a HEPA filter (HEPA capsule, Model PN 12144; Pall Corporation, Port Washington, NY, USA) inserted into the sample stream; and (iv) mercury-free air supplied by a Tekran 1100 unit zero-air generator for comparison to clean, charcoal-filtered air. The ozone denuder (ChemComb Model 3500 Speciation Sampling Cartridge, Thermo Electron Corporation, East Greenbush, NY, USA) was coated with a potassium carbonate and sodium nitrite solution in methanol and nanopure-grade water. We performed slow wavelength scans over the $\mathrm{Hg}^{0}$ ab- sorption spectrum and nearby forbidden oxygen transitions for all ambient air measurements, and three replicate scans were performed for each for the respective sampling arrangements.

Mass concentrations of $\mathrm{Hg}^{0}$ vapor generated in the laboratory and from ambient-air were routed in series through the CRDS cell followed by a Tekran 2537B vapor-phase mercury analyzer. The 2537B instrument collects the air stream on two gold cartridges, followed by thermal desorption and detection by cold vapor atomic fluorescence spectrometry at $253.65 \mathrm{~nm}$. Use of dual gold cartridges allowed alternate sampling and desorption, resulting in continuous measurement of $\mathrm{Hg}^{0}$ on a predefined time base. The model 2537B was recalibrated every $24 \mathrm{~h}$ using its internal permeation source with sample flow rate set to $11 \mathrm{~min}^{-1}$. We measured blanks for the 2537B during each calibration, and these measurements consistently yielded mercury mass concentration of $0.00 \mathrm{ng} \mathrm{m}^{-3}$. Set-up, accuracy, and precision of this instrument have been evaluated previously (e.g., Ebinghaus et al., 1999; Schroeder et al., 1995), and the manufacturer reports a detection limit for $5 \mathrm{~min}$ samples of $0.10 \mathrm{ng} \mathrm{m}^{-3}$.

\section{Measured spectral profiles, instrument performance, and instrument comparisons}

\section{1 $\quad \mathrm{Hg}^{0}$ spectral profiles and comparisons to theoretical values}

CRDS measurements of pressure-broadened absorption spectra between $253.61 \mathrm{~nm}$ and $253.66 \mathrm{~nm}$ for different $\mathrm{Hg}^{0}$ concentrations (i.e., 46 to $535 \mathrm{ng} \mathrm{m}^{-3}$ ) supplied to the CRDS cell are shown in Fig. 3. The $\mathrm{Hg}^{0}$ absorption line can be located clearly at $253.65 \mathrm{~nm}$, and the presence of a series of forbidden oxygen absorption lines is observed between 253.57 and $253.62 \mathrm{~nm}$. Such forbidden oxygen absorption lines in the UV have been reported before (e.g., Tao et al., 


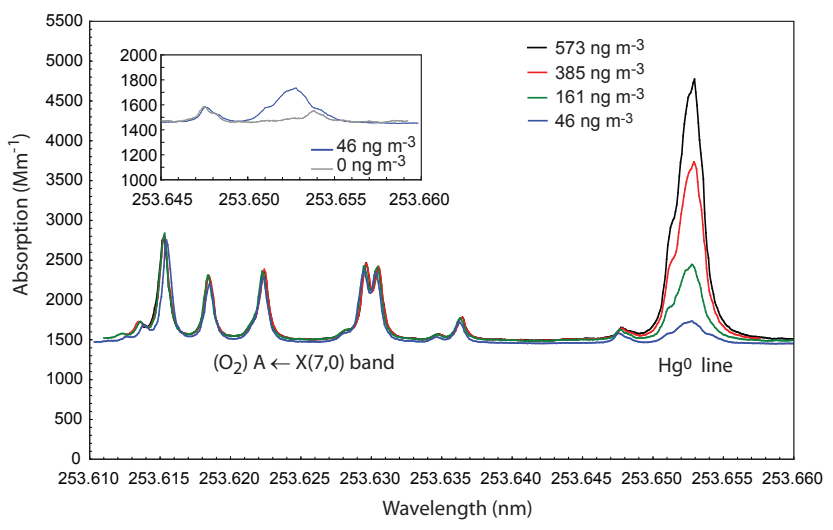

Fig. 3. Wavelength scans of CRDS absorption measured for different $\mathrm{Hg}^{0}$ concentrations for wavelengths between 253.61 and $253.66 \mathrm{~nm}$. The $\mathrm{Hg}^{0}$ absorption line is located at $253.653 \mathrm{~nm}$, and forbidden molecular oxygen absorption lines are observed between 253.61 and $253.64 \mathrm{~nm}$. A scan of the $\mathrm{Hg}^{0}$ absorption line measured with a cavity flushed with mercury-free air is reported in inset panel and shows a residual oxygen absorption line overlapping with the $\mathrm{Hg}^{0}$ absorption line.

2000). Due to the relatively constant atmospheric $\mathrm{O}_{2}$ content, such oxygen absorption lines have been used for additional instrument calibration and quality assurance in ambient air as demonstrated for measurement of aerosol light absorption (Tian et al., 2009). The insert panel of Fig. 3 shows details of absorption measurements at 253.65 (i.e., the $\mathrm{Hg}^{0}$ absorption line) for $\mathrm{Hg}^{0}$ concentrations of $0 \mathrm{ng} \mathrm{m}^{-3}$ (flushed with mercury-free air) and $46 \mathrm{ng} \mathrm{m}^{-3}$. These measurements clearly observe a residual absorption peak at a wavelength of only $+0.001 \mathrm{~nm}$ above the mercury absorption peak. This peak very likely is due to oxygen absorption as it disappears for an $\mathrm{N}_{2}$-filled cell.

Figure 4 shows direct (i.e., non-CRDS) transmission spectra from 253.64 to $253.66 \mathrm{~nm}$ for mercury cells either filled with high (i.e., $80 \mathrm{kPa}$; near ambient) $\mathrm{N}_{2}$ pressure or evacuated to low pressure (i.e., $1.3 \times 10^{-5} \mathrm{~Pa}$ ). Specifically, Fig. 4 reports ratios between PD1 and PD2 voltages rescaled to remove reflection losses on the two uncoated window surfaces of each cell (20\% losses estimated from signal without cells present) and normalized. The $80 \mathrm{kPa}$ profile is clearly pressure-broadened, while the low-pressure profile reveals the hyperfine structure of the ${ }^{1} \mathrm{~S}_{0}{ }^{3} \mathrm{P}_{1}$ transition of $\mathrm{Hg}^{0}$ with the presence of five distinct absorption isotope peaks as described by others (Anderson et al., 2007; Carruthers et al., 2005; Scheid et al., 2007; Spuler et al., 2000).

We calculated theoretical absorption coefficients as a function of wavelength for $\mathrm{Hg}^{0}$ using a computer program based on previous work by Finkelstein (1998). This model includes Lorentzian and Gaussian linewidth components described above in Sect. 2.1. Specifically, a mercury self-pressure broadening coefficient of $7.60 \times 10^{4} \mathrm{~Hz} \mathrm{~Pa}^{-1}$ (Finkelstein, 1998) and a foreign-pressure broadening co- efficient of $7.46 \times 10^{4} \mathrm{~Hz} \mathrm{~Pa}^{-1}$ for atomic mercury broadened by $\mathrm{N}_{2}$ (Anderson et al., 2007) were used. We validated our model and its parameterization by modeling a published spectrum (Scheid et al., 2007), which was obtained with a very narrowband (e.g., laser linewidth of about $10 \mathrm{MHz}$ ), continuous-wave, solid-state laser. Because we used a spectrally much wider pulsed dye laser, we additionally accounted for laser linewidth and shape in the calculations to reproduce our absorption spectra. A large number of model spectra using different combinations of laser linewidth, shape, and cell temperature were generated, and the best fit was determined by minimizing the sum of the squared differences between measurements and model value for $0.1 \mathrm{GHz}$ frequency resolution spectra. Specifically, Gaussian and Lorentzian contributions to the laser linewidth from 0 to $3 \mathrm{GHz}$ were included, and temperature was varied between 273 and $290 \mathrm{~K}$. Mercury vapor pressure in an $\mathrm{Hg}^{0}$ cell depends on the temperature of liquid mercury held in a sealed tube extending from the bottom of the cell and maintained in an ice bath. It is likely that the sealed tube we used was too small for efficient cooling of the liquid mercury down to $273 \mathrm{~K}$, as previously observed by Anderson et al. (2007) with a similar setup. The best fit of our high pressure measured spectra is shown in Fig. 4 and was obtained for $280 \mathrm{~K}$ and a laser linewidth modeled with Gaussian and Lorentzian contributions with full-widths-at-half-maximum (FWHM) of 1.8 and $0.2 \mathrm{GHz}$, respectively. Figure 4 shows that our modeled and experimental spectrums for the high pressure (i.e., $80 \mathrm{kPa}) \mathrm{Hg}^{0}$ cell are in excellent agreement. As expected, our modeled laser FWHM was about twice the factory specification of $0.9 \mathrm{GHz}$ reported for the Sirah Dye laser operating in the green, before frequency doubling. Finally, modeling our absorption measurements led to an absorption cross section for $\mathrm{Hg}^{0}$ of $2.4 \times 10^{-14} \mathrm{~cm}^{2}$ atom ${ }^{-1}$, a value lower than the value of $3.3 \times 10^{-14} \mathrm{~cm}^{2}$ atom ${ }^{-1}$ previously reported by Edner et al. (1989) and Spuler et al. (2000).

The experimental absorption spectrum for the low pressure (i.e., $1.3 \times 10^{-5} \mathrm{~Pa}$ ) $\mathrm{Hg}^{0}$ cell, also reported in Fig. 4, clearly shows the hyperfine structure of $\mathrm{Hg}^{0}$ absorption with its five individual peaks. However, peak absorption at low $\mathrm{Hg}^{0}$ pressure is less than at high pressure, likely due to saturation of the transition at our relatively high laser power due to slower relaxation to the ground state than at high pressure because of the greatly reduced collision frequency. As saturation of the transition is currently not included in our spectral model, we did not model the low pressure spectra.

The distinct peak of the ${ }^{202} \mathrm{Hg}$ isotope absorption at $253.6531 \mathrm{~nm}$ wavelength seen in the low pressure spectrum (see label on Fig. 4) was used to exactly position the laser wavelength for $\mathrm{Hg}^{0}$ absorption measurements using the computer-controlled Littrow grating of the dye laser. We also used the same low-pressure ${ }^{202} \mathrm{Hg}$ absorption peak for wavelength positioning of the differential "off-line" measurement as described in detail below. 


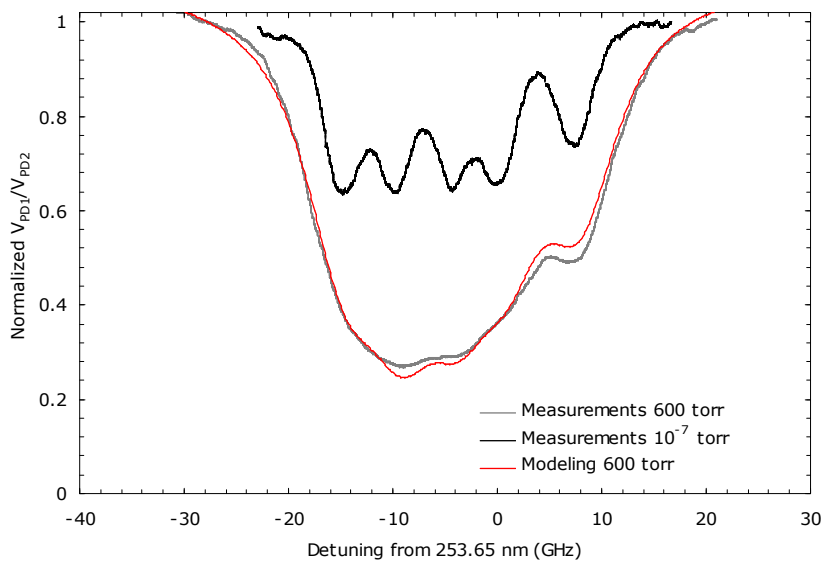

Fig. 4. Absorption spectra of the $\mathrm{Hg}^{0}{ }^{1} \mathrm{~S}_{0^{-}}{ }^{3} \mathrm{P}_{1}$ transition in a high pressure cell ( $80 \mathrm{kPa}$ of $\mathrm{N}_{2}$ buffer gas, grey line) and an evacuated low pressure cell $\left(1.3 \times 10^{-5} \mathrm{~Pa}\right.$, black line $)$ with a natural isotope mixture. The spectrum from the low pressure cell clearly shows the hyperfine structure of the ${ }^{1} \mathrm{~S}_{0^{-}}{ }^{3} \mathrm{P}_{1}$ transition of $\mathrm{Hg}^{0}$. A theoretical model of the spectrum from the high pressure cell is shown in red and faithfully reproduces the experimental spectrum.

\section{2 $\mathrm{Hg}^{0}$ absorption measurements, comparisons with a Tekran 2537B analyzer}

\subsubsection{Laboratory-generated $\mathrm{Hg}^{\mathbf{0}}$ vapor concentrations}

We connected the $\mathrm{Hg}^{0}$ vapor generation system to the CRDS cavity to supply a range of $\mathrm{Hg}^{0}$ concentrations and connected a Tekran 2537B analyzer directly downstream of the cavity for corresponding measurements of $\mathrm{Hg}^{0}$ concentrations with 5-min time resolution. $\mathrm{Hg}^{0}$ vapor concentrations were supplied to the cavity at a flow rate of $11 \mathrm{~min}^{-1}$ and allowed to stabilize at a constant level for at least $10 \mathrm{~min}$ (i.e., two sampling cycles of the 2537B analyzer; $\Delta \mathrm{Hg}^{0}<0.1 \mathrm{ng} \mathrm{m}^{-3}$ ). For each measurement, we calibrated the system for extinction losses other than $\mathrm{Hg}^{0}$ absorption CRDS losses by shifting the laser wavelength "off-line" of the $\mathrm{Hg}^{0}$ absorption spectrum, as described below. Specifically, $\mathrm{Hg}^{0}$ absorption was measured in the cavity with CRDS during $10 \mathrm{~s}$ long measurements by tuning the laser wavelength to the peak of the ${ }^{202} \mathrm{Hg}$ hyperfine absorption line, as described in Sect. 3.3. To measure "off-line" background extinction (i.e., extinction losses other than $\mathrm{Hg}^{0}$ absorption: mirror losses, $\alpha_{\mathrm{M}}$, and background extinction, $\alpha_{\mathrm{BG}}$; see Eq. 3), we shifted the laser wavelength by $-0.02 \mathrm{~nm}$ off peak ${ }^{202} \mathrm{Hg}$ absorption (i.e., offline) immediately after the "on-line" measurements using a computer-controlled Littrow grating in the dye laser. $\mathrm{Hg}^{0}$ absorption was determined as a differential measurement between these on-line and off-line absorption measurements, and measurements were repeated six times for each $\mathrm{Hg}^{0}$ concentration shown in Fig. 4. In addition, we performed differential measurements of the cell supplied with $\mathrm{Hg}^{0}$-free air to measure the background extinction difference between "online" and "off-line" measurements in the absence of $\mathrm{Hg}^{0}$, and all data were corrected for this offset.

The vapor generation system could supply $\mathrm{Hg}^{0}$ concentrations ranging from $0.2 \mathrm{ng} \mathrm{m}^{-3}$ to $573 \mathrm{ng} \mathrm{m}^{-3}$. Our generation vapor setup provided very stable $\mathrm{Hg}^{0}$ concentrations during periods as long as $30 \mathrm{~min}$, generally within a $0.05 \mathrm{ng} \mathrm{m}^{-3}$ range as assessed by 5 -min resolution $\mathrm{Hg}^{0}$ Tekran measurements. Figure 5a-d shows direct comparisons between $\mathrm{Hg}^{0}$ absorption coefficients $\alpha_{\mathrm{Hg}}$ obtained from the CRDS and $\mathrm{Hg}^{0}$ concentrations as measured by the 2537B analyzer over the range tested. We observed excellent linear correlations between CRDS measurements and the 2537B analyzer across the whole range of $\mathrm{Hg}^{0}$ concentrations with a coefficient of variability, $r^{2}$, of more than 0.99 and a linear slope of $6.03 \mathrm{Mm}^{-1} / \mathrm{ng} \mathrm{m}^{-3}$. Only $\mathrm{Hg}^{0}$ concentrations lower than $50 \mathrm{ng} \mathrm{m}^{-3}$ (Fig. $5 \mathrm{~b}$; $90 \%$ of the data) were considered to accurately evaluate the slope and avoid bias due to higher and isolated values. The relationship demonstrated that both analyzers show an excellent, linear response through a large range of $\mathrm{Hg}^{0}$ concentrations, which is an impressive result given the different mechanism of detection of the two approaches (i.e., pre-concentrations and atomic fluorescence detection versus CRDS detection). Figure $5 \mathrm{c}$ details performance of the CRDS at low-level $\mathrm{Hg}^{0}$ concentrations in the 0.2 to $6 \mathrm{ng} \mathrm{m}^{-3}$ range, with a particularly important range of below $1.7 \mathrm{ng} \mathrm{m}^{-3}$ representing sub-ambient $\mathrm{Hg}^{0}$ concentrations. Even at this low range, the relationship between measured $\mathrm{Hg}^{0}$ concentrations and CRDS absorption is still highly linear $\left(r^{2}>0.99\right)$. Error bars reported on CRDS absorption data represent three standard errors calculated for a $10 \mathrm{~s}$ time resolution (see Sect. 4.3 and Table 2), and Tekran error bars correspond to three times standard deviation of individual 5-min observations (2\% of the background concentrations; i.e., $3 \times 0.03 \mathrm{ng} \mathrm{m}^{-3}=0.09 \mathrm{ng} \mathrm{m}^{-3}$, E. Prestbo, personal communication, 2008, Tekran Inc. Canada).

Figure 5d shows results of $1 \mathrm{~s}$ CRDS absorption measurements obtained by difference between the last second of each on-line $10 \mathrm{~s}$ measurement and the first second of each off-line $10 \mathrm{~s}$ measurement. Errors bars reported on Fig. 5d represent three standards errors calculated for a 1-s time resolution (see Sect. 4.3 and Table 2). We observed similar mean concentrations at this high temporal resolution, and results are still highly linear to respective $\mathrm{Hg}^{0}$ concentration measurements observed at 5-min resolution. Both Figs. 5c and d, however, indicate that low-level $\mathrm{Hg}^{0}$ measurements show higher variability between individual replicates, that is, repeated comparisons of CRDS and $\mathrm{Hg}^{0}$ Tekran measurements with a constant $\mathrm{Hg}^{0}$ concentration flushed through the cell. This indicates that either one or both of the two detection methods approaches its sensitivity or detection limits, or that the supply rate of $\mathrm{Hg}^{0}$ injected into the instruments may show some low-level concentration fluctuations. Section 4.3 discusses possible reasons and uncertainties in CRDS detection. 

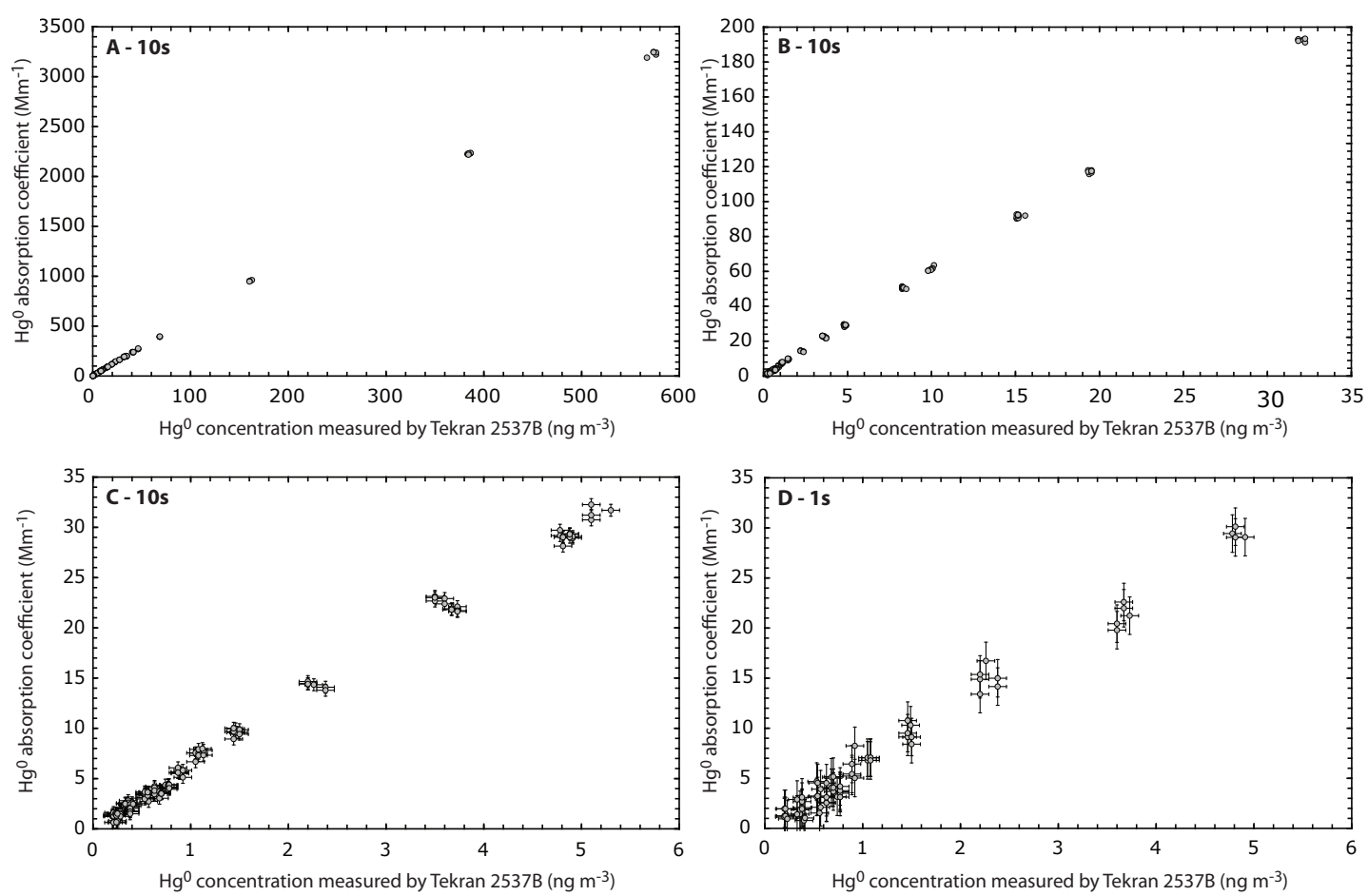

Fig. 5. Direct comparison of $\mathrm{Hg}^{0}$ absorption coefficients measured by the CRDS system and Tekran $2537 \mathrm{~B}$ analyzer $\mathrm{Hg}^{0}$ mass concentrations ranging from 0.2 to $573 \mathrm{ng} \mathrm{m}^{-3} \mathbf{A}$, from 0.2 to $35 \mathrm{ng} \mathrm{m}^{-3} \mathbf{B}$, and from 0.2 to $6 \mathrm{ng} \mathrm{m}^{-3} \mathbf{C}$ and $\mathbf{D}$. Panels A, B, and C show $10 \mathrm{~s}$ averaged values, and error bars are three standard errors at $10 \mathrm{~s}$ time resolution. Panel D reports $1 \mathrm{~s}$ averaged values, and errors bars represent three standard errors for a $1 \mathrm{~s}$ time resolution. For all panels, the error bars reported for the Tekran data correspond to three standard deviations of individual 5-min observations (i.e., $0.09 \mathrm{ng} \mathrm{m}^{-3}$ ).

\subsubsection{Ambient-air $\mathrm{Hg}^{\mathrm{0}}$ vapor concentration measurements}

Ambient air measurements at 1-s time resolution using outside air drawn into the cavity are shown in Fig. 6a and b. Measurements include triplicate wavelength scans performed for (i) ambient air with a $0.2 \mu \mathrm{m}$ cutpoint particulate filter (dark blue lines); (ii) ambient air with a $0.2 \mu \mathrm{m}$ cutpoint particulate filter and an ozone denuder (light blue lines; (iii) ambient air with a HEPA filter and ozone denuder (red lines). Comparison scans included (iv) air supplied by an $\mathrm{Hg}$-free air generator (charcoal filtered air; black lines). The scans of the laser wavelength show differences due to extinction from ultra-fine particulate matter (PM; diameter $<0.2 \mu \mathrm{m}$ ) and extinction due to ambient ozone. These differences are, within the scan from $253.647 \mathrm{~nm}$ to $253.654 \mathrm{~nm}$, independent of wavelength and can be interpreted by looking at the wavelength-averaged extinction values.

Extinction of the CRD cavity filled with zero air, generated by the Tekran model 1100 zero-air generator, is $1407 \pm 36 \mathrm{Mm}^{-1}$, which was indistinguishable from the extinction of the cavity filled with ambient air filtered by the HEPA-type particle filter and ozone denuder $\left(1422 \pm 20 \mathrm{Mm}^{-1}\right)$ through most of the scanned wavelength spectrum (exception of the $\mathrm{Hg}^{0}$ absorption; see Fig. $6 \mathrm{~b}$ and discussion below). This demonstrates that ambient air extinction in the near vicinity of the $\mathrm{Hg}^{0}$ absorption wavelength is caused by ozone and fine PM. If the HEPA filter is removed from this setup, the cavity filled with ambient air filtered with an $0.2 \mu \mathrm{m}$ cutpoint particle filter, followed by an ozone denuder, has an extinction of $1711 \pm 20 \mathrm{Mm}^{-1}$, corresponding to an extinction of about $289 \mathrm{Mm}^{-1}$ due to ultra-fine $\mathrm{PM}$. This extinction corresponds to a typical ambient ultrafine PM mass concentration of about $18 \mu \mathrm{g} \mathrm{m}^{-3}$, assuming an ultra-fine PM extinction efficiency of $16 \mathrm{~m}^{2} \mathrm{~g}^{-1}$ at $254 \mathrm{~nm}$. Removing the ozone denuder yields a cavity filled with ambient air filtered only by the $0.2 \mu \mathrm{m}$ cutpoint particle filter with an extinction of $2224 \pm 14 \mathrm{Mm}^{-1}$, corresponding to an ozone extinction of about $513 \mathrm{Mm}^{-1}$. For an ozone absorption coefficient of $15.9 \mathrm{Mm}^{-1} \mathrm{ppb}^{-1}$ (Molina and Molina, 1986), this corresponds to an ambient ozone concentration of $32.6 \mathrm{ppb}$. Ozone and ultra-fine PM concentrations consistent with these measurements are in a range typically found in wintertime Reno, Nevada, USA.

Unfiltered ambient air also shows higher variability in absorption compared to zero air and ambient air free of ozone and fine PM. We attribute this to concentration fluctuations of ozone and fine particulates, and hence these observed patterns emphasize the need to account for interferences of 

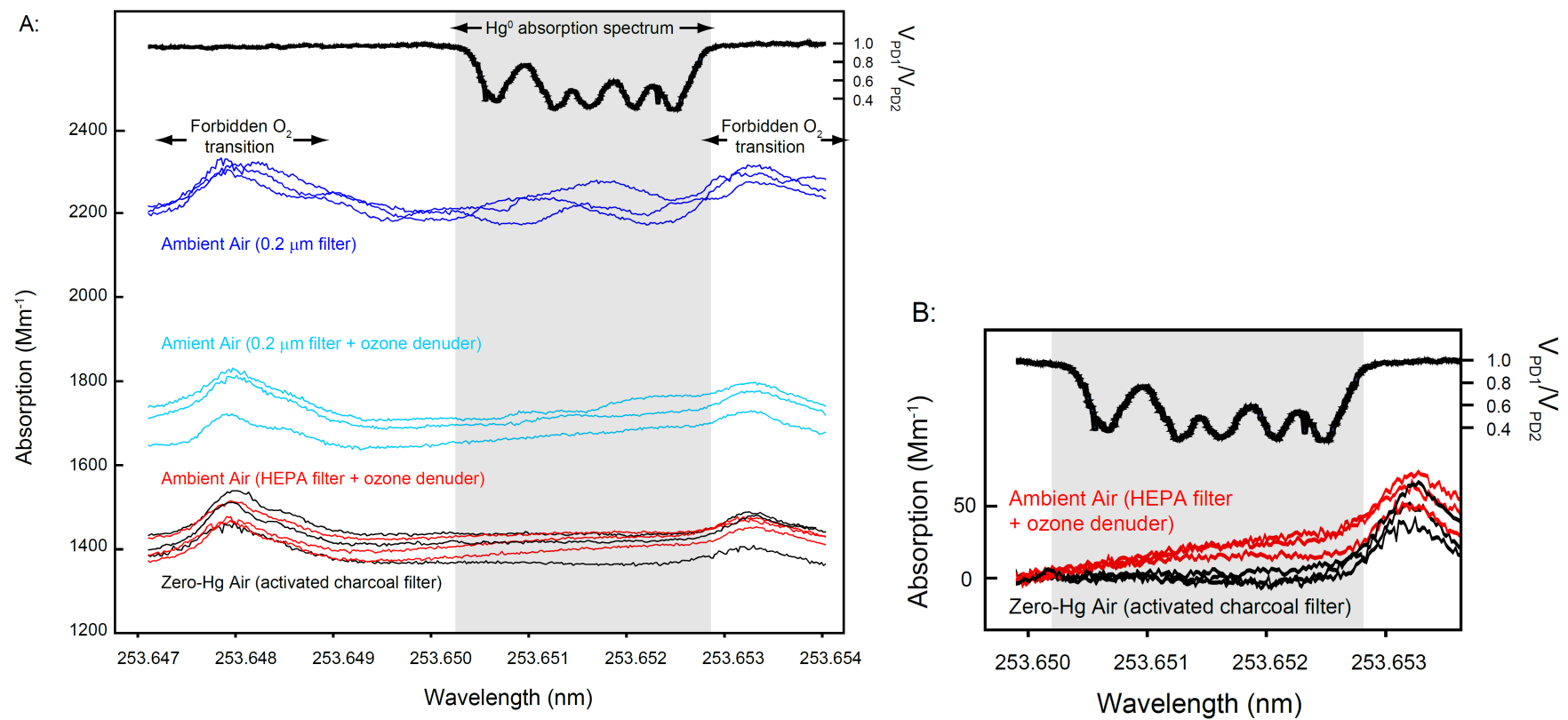

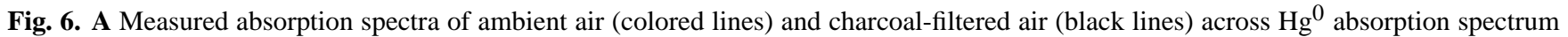
and nearby forbidden oxygen lines. Dark blue lines represent ambient air with a $0.2 \mu \mathrm{m}$ cutpoint particulate filter; light blue lines represent ambient air with a $0.2 \mu \mathrm{m}$ cutpoint particulate filter and ozone denuder; red lines represent ambient air with a HEPA filter and ozone denuder; and black lines represent air supplied by an $\mathrm{Hg}$-free air generator (Tekran Model 1100 zero air generator). B Detailed look of the wavelength scans of $\mathrm{Hg}$-free air and ambient air free of ozone and fine PM. Lines are standardized to background absorption immediately below the $\mathrm{Hg}^{\mathrm{O}}$ absorption wavelength (i.e., set to $0 \mathrm{Mm}^{-1}$ absorption).

Table 2. Detection limits-equivalent to sensitivities-of the CRDS prototype at different time resolutions. Absorptions $\left(\mathrm{Mm}^{-1}\right)$ were converted to concentrations $\left(\mathrm{ng} \mathrm{m}^{-3}\right)$ using the conversion factor measured during comparison with the 2537B Tekran gas-phase analyzer (experimental approach).

\begin{tabular}{ccc}
\hline $\begin{array}{c}\text { Time } \\
\text { resolution } \\
(\mathrm{s})\end{array}$ & $\begin{array}{c}\text { Sensitivity, } \\
\text { detection limit } \\
\left(\mathrm{Mm}^{-1}\right)\end{array}$ & $\begin{array}{c}\text { Experimental sensitivity, } \\
\text { detection limit } \\
\left(\mathrm{ng} \mathrm{m}^{-3}\right)\end{array}$ \\
\hline 0.1 & 5.90 & 0.98 \\
1 & 1.87 & 0.31 \\
10 & 0.59 & 0.10 \\
30 & 0.34 & 0.06 \\
\hline
\end{tabular}

ozone and fine particulates. This can be achieved in three ways: first, ozone and fine PM can be filtered out as shown in Fig. 6a; (ii) interference can be explained by corresponding measurements of ozone and fine particulate concentrations and theoretical adjustment; or (iii) fast, high-frequency tuning of the laser from "offline" to "online" of the $\mathrm{Hg}^{0} \mathrm{ab}$ sorption spectrum allows for differential absorption measurements and continuously accounts for interferences of ozone and fine PM. This latter approach seems particularly useful since both ozone and fine PM absorption are constant in the vicinity of the narrow $\mathrm{Hg}^{0}$ absorption spectrum. This approach also allows for continuous calibration of variability in system background extinction losses and other interferences such as laser or PMT power fluctuations (see also discussion below).

Figure $6 \mathrm{~b}$ shows a more detailed look at the wavelength scans of $\mathrm{Hg}$-free air and ambient air free of ozone and fine $\mathrm{PM}$ across the $\mathrm{Hg}^{0}$ absorption spectrum. Lines are standardized to the background absorption immediately below the $\mathrm{Hg}^{0}$ absorption wavelength (i.e., set to $0 \mathrm{Mm}^{-1}$ absorption). All ambient air graphs show the presence of $\mathrm{Hg}^{0}$, clearly highlighting that ambient $\mathrm{Hg}^{0}$ can be detected at 1-s time resolution by our CRDS system. Absorption of ambient $\mathrm{Hg}^{0}$, however, is variable, ranging between approximately 9 and $23 \mathrm{Mm}^{-1}$ depending on position within $\mathrm{Hg}^{0}$ absorption spectra and replicate scans. These results emphasize a need for exact laser wavelength positioning during measurements, which in our CRDS system can be implemented using the external mercury cell. Using the experimental relationship between absorption and $\mathrm{Hg}^{0}$ of $6.03 \mathrm{Mm}^{-1} / \mathrm{ng} \mathrm{m}^{-3}$ (discussed above), the calculated concentration range is 1.5 to $3.8 \mathrm{ng} \mathrm{m}^{-3}$. Corresponding Tekran 2537B measurements showed $\mathrm{Hg}^{0}$ concentrations between 2.0 and $2.3 \mathrm{ng} \mathrm{m}^{-3}$ for the ambient scans and $0.0 \mathrm{ng} \mathrm{m}^{-3}$ for $\mathrm{Hg}$-free air. We attribute variability in CRDS ambient $\mathrm{Hg}^{0}$ measurements to fluctuations in background extinction of the system, possibly 
induced by variability in laser power or PMT instability. Indication for such instability is evident by variable peak heights and shapes of adjacent oxygen lines which theoretically should be identical in all scans due to constant $\mathrm{O}_{2}$ concentrations. A solution to address such variability is to continuously account for background system extinction variability by frequent and high-frequency "online/offline" tuning of the laser wavelength, as further discussed in Sect. 6.

\subsection{Theoretical calculation of $\mathrm{CRDS} \mathrm{Hg}^{0}$ detection limits}

Pulse-to-pulse laser signal variability of the CRDS $\mathrm{Hg}^{0}$ absorption losses at $253.65 \mathrm{~nm}$ has been used to estimate the sensitivity and detection limits of our CRDS prototype. The detection limit is defined as the threshold where the $\mathrm{Hg}^{0} \mathrm{ab}$ sorption information is lost in the signal noise (i.e., detection limit is the same as instrument sensitivity for the CRDS approach). At $\mathrm{Hg}^{0}$ concentrations lower than $50 \mathrm{ng} \mathrm{m}^{-3}$, we consistently observed a standard deviation of the CRD signal between 3.7 and $4.6 \mathrm{Mm}^{-1}$, with an average value of $4.4 \mathrm{Mm}^{-1}$. Similar pulse-to-pulse variability also was observed for all baseline measurements (i.e. when the laser wavelength was tuned "off" the mercury absorption line). For higher $\mathrm{Hg}^{0}$ concentrations, however, pulse-to-pulse variability increased and reached a maximum at $573 \mathrm{ng} \mathrm{m}^{-3}$, at about $2 \%$ of the measured absorption signal. The reasons for this increase in pulse-to-pulse noise at higher $\mathrm{Hg}^{0}$ levels are currently unclear.

Table 2 reports absorption sensitivities (similar to detection limits) in $\mathrm{Mm}^{-1}$ defined as three standard errors for different averaging times and based on the mean standard deviation observed for the CRDS signal for more than 200 measurements (i.e., $4.4 \mathrm{Mm}^{-1}$ ). Experimental sensitivities in $\mathrm{ng} \mathrm{m}^{-3}$ also shown in Table 2 were obtained applying the conversion factor determined from comparison of our CRDS instrument with the Tekran 2537B analyzer (i.e., $6.03 \mathrm{Mm}^{-1} / \mathrm{ng} \mathrm{m}^{-3}$ ). Theoretical sensitivities in $\mathrm{ng} \mathrm{m}^{-3}$, calculated using the $\mathrm{Hg}^{0}$ absorption cross section of $2.4 \times 10^{-14} \mathrm{~cm}^{2}$ atom ${ }^{-1}$ determined by modeling the hyperfine structure of the ${ }^{1} \mathrm{~S}_{0}{ }_{-}^{3} \mathrm{P}_{1}$ mercury transition (see Sect. 4.1) and Eq. (4), were $21 \%$ lower than experimental values reported in Table 2 . At $1 \mathrm{~Hz}$, our CRDS prototype showed an experimental sensitivity of $0.31 \mathrm{ng} \mathrm{m}^{-3}$. Since increases in CRDS averaging time (i.e., decreases in time resolution of the measurements) led to decreases in CRDS detection limit, this value greatly decreases with longer average times (e.g., to $0.06 \mathrm{ng} \mathrm{m}^{-3}$ at $30 \mathrm{~s}$ average times). These detection limits are based purely on pulse-to-pulse signal variability, and many other factors may make it challenging to reach such low detection limits. The calculation, however, holds promising evidence that the CRDS approach is a feasible technology for use in atmospheric studies requiring $\mathrm{Hg}^{0}$ detection at background levels and below (i.e., $\leq 1.7 \mathrm{ng} \mathrm{m}^{-3}$ ).

www.atmos-chem-phys.net/10/2879/2010/

\section{Challenges and uncertainties in measurements}

\subsection{Uncertainty in $\mathrm{Hg}^{0}$ absorption cross section}

Calculations of $\mathrm{Hg}^{0}$ concentrations based on CRDS absorption measurements and using Eq. (4) with an $\mathrm{Hg}^{0}$ absorption cross section, $\sigma_{\mathrm{Hg}}$, of $2.4 \times 10^{-14} \mathrm{~cm}^{2}$ atom $^{-1}$, yielded a conversion factor of $7.33 \mathrm{Mm}^{-1} / \mathrm{ng} \mathrm{m}^{-3}$. Consequently, our Tekran-based $\mathrm{Hg}^{0}$ concentrations (i.e., experimental approach) were $21 \%$ higher than $\mathrm{Hg}^{0}$ concentrations predicted by the theory. Using the higher value of $\sigma_{\mathrm{Hg}}$, $3.3 \times 10^{-14} \mathrm{~cm}^{2}$ atom ${ }^{-1}$, reported by Spuler et al. (2000) would further increase the discrepancies between theoretical and Terkan-based $\mathrm{Hg}^{0}$ concentrations. Currently, we do not understand these discrepancies.

Accuracy and precision of the Tekran 2537B analyzer have been evaluated in a number of studies (e.g., Ebinghaus et al., 1999; Schroeder et al., 1995), and we do not doubt its reliance. The internal permeation source used for daily calibration of the Tekran 2537B analyzer has been checked by external injection of known quantity of $\mathrm{Hg}^{0}$ vapor in our laboratory, and synchronized measurements using a second Tekran analyzer connected with a common line yielded measurements within $4 \%$ of each other. It is possible that there may be some inherent problem with the modeling approach used for calculation of the $\mathrm{Hg}^{0}$ absorption cross section in our study, as well as in previous studies. Further development of our absorption model including addition of saturation processes may help to evaluate this problem. Until this issue is resolved, however, we calibrate our CRDS measurements by comparison with Tekran 2537B measurements yielding a calibration factor of $6.03 \mathrm{Mm}^{-1} / \mathrm{ng} \mathrm{m}^{-3}$ and corresponding to a Tekran/CRDS-based absorption cross section for $\mathrm{Hg}^{0}$ of $1.9 \times 10^{-14} \mathrm{~cm}^{2}$ atom ${ }^{-1}$.

\subsection{Variability of repeated CRDS absorption measurements at constant $\mathrm{Hg}^{\mathbf{0}}$ levels}

Figure $5 \mathrm{c}$ shows that at low $\mathrm{Hg}^{0}$ concentrations between 0.2 and $6.0 \mathrm{ng} \mathrm{m}^{-3}$, some variability was observed in multiple $10 \mathrm{~s}$ CRDS absorption measurements that were tested within respective 5-min duration Tekran observations. An inherent problem in advancing temporal resolution of sensors is that high-frequency comparisons to lower time-resolution sensors are impossible. Hence, it is possible that the variability of repeated CRDS absorption signals at seemingly constant $\mathrm{Hg}^{0}$ levels could be due to true high temporal resolution fluctuations in $\mathrm{Hg}^{0}$ concentrations during measurements, and that the $\mathrm{Hg}^{0}$ supply source - seemingly delivering constant $\mathrm{Hg}^{0}$ concentrations when time averaged and quantified over the $5 \mathrm{~min}$ duration of the Tekran measurements - exhibits fluctuations in $\mathrm{Hg}^{0}$ concentrations. To assess this possibility, we investigated at $253.65 \mathrm{~nm}$ (i.e., at the $\mathrm{Hg}^{0}$ line) temporal variability in the CRDS absorption signals across a 5 -min time span while stable $\mathrm{Hg}^{0}$ vapor 


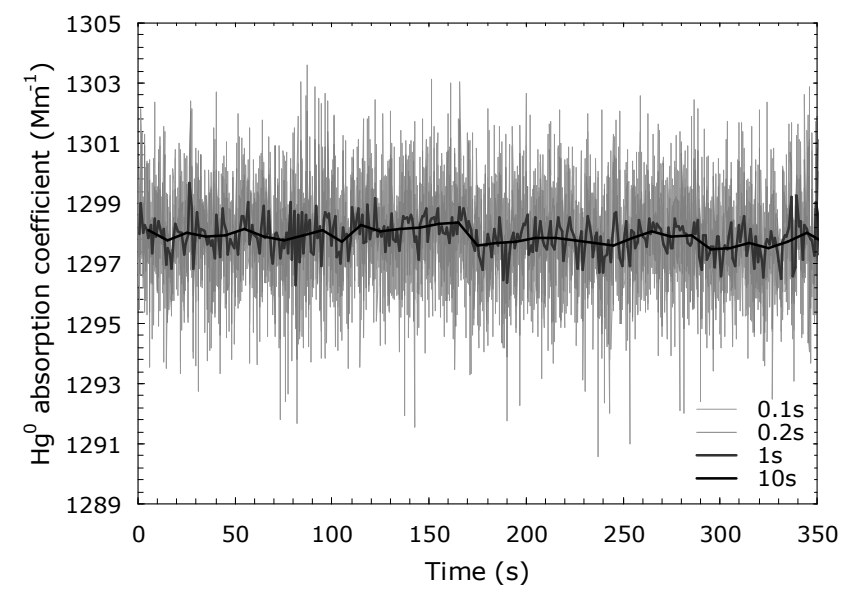

Fig. 7. Temporal variability of the total absorption signal including background and mirror losses at different time resolutions while a stable $\mathrm{Hg}^{0}$ vapor concentration (i.e., $0.8 \mathrm{ng} \mathrm{m}^{-3}$ ) was supplied to the cavity for a $\sim 5$-min time span.

concentrations were supplied to the cavity by the permeation system $\left(0.8 \mathrm{ng} \mathrm{m}^{-3}, \Delta \mathrm{Hg}^{0}<0.1 \mathrm{ng} \mathrm{m}^{-3}\right.$ over four sampling cycles of the 2537B analyzer). Figure 7 shows temporal variability in total absorption at different sampling frequencies. For each time resolution reported, we evaluated the maximum difference between the absorption value averaged over 5 min (i.e., $1297.87 \mathrm{Mm}^{-1}$ ) and individual absorption values. Fluctuations of individual measurement from the 5-min averaged value were always lower than our instrument detection limits estimated previously for the corresponding time resolutions (cf. Sect. 4.3 and Table 2). For example, maximum variation between the $10 \mathrm{~Hz}$ absorption signal and the 5 -min average was $0.46 \mathrm{Mm}^{-1}$, when we estimated our instrument detection limit at $10 \mathrm{~Hz}$ to be $0.59 \mathrm{Mm}^{-1}$.

These results indicate that the $\mathrm{Hg}^{0}$ supply source was stable, and higher frequency temporal variations in $\mathrm{Hg}^{0}$ concentrations were unlikely to affect our instrument comparisons. We used a cavity that was sealed air-tight for several hours and was hence removed from potential $\mathrm{Hg}^{0}$ concentration fluctuations from permeation source and the environment to further investigate the temporal variability in absorption signal during 5-min periods. We observed similar patterns as the ones reported in Fig. 7, confirming that variability in multiple CRDS absorption measurements may be due to system fluctuations discussed in the following section. Interestingly, direct evaluations of standard deviations of the absorption signals at all time resolutions reported in Fig. 7 agree well with previously reported sensitivities (Table 2) based on the $50 \mathrm{~Hz}$ standard deviation (divided by the square root of the number of averaged measurements). These experimental data thus confirm the scaling of our CRDS prototype detection limit with the inverse square root of averaging time.

\subsection{Possible interferences due to background/mirror extinction fluctuations, unstable baseline absorption losses, and laser wavelength tuning}

During "online-offline" wavelength tuning using the computer-controlled Littrow grating in dye resonator, we found slight offsets in absorption baseline losses despite careful locking of the laser wavelength to the peak absorption line of the ${ }^{202} \mathrm{Hg}$ isotope in the low pressure $\mathrm{Hg}^{0}$ cell. Such offset was low (in the range of $\sim 0.1 \%$ of baseline absorption), but this effect could contribute to variability when the CRDS operates close to its detection limit.

Equation (3) shows that the total measured CRDS signal extinction is dependent on the $\mathrm{Hg}^{0}$ absorption coefficient $\left(\alpha_{\mathrm{Hg}}\right)$ and on (i) background extinction due to other gases and/or particulate absorption and scattering $\left(\alpha_{\mathrm{BG}}\right)$ plus (ii) extinction due to mirror losses $\left(\alpha_{M}\right)$. To calibrate for these losses, we performed differential "online/offline" measurements through wavelength tuning with the assumption that these losses (i.e., $\alpha_{\mathrm{BG}}$ and $\alpha_{\mathrm{M}}$ ) stay constant across the short wavelength shift of $0.02 \mathrm{~nm}$. If losses are dependent even to a low degree on the wavelength shift, this may cause some variability specifically at low $\mathrm{Hg}^{0}$ concentrations where the $\mathrm{Hg}^{0}$ absorption coefficient $\left(\alpha_{\mathrm{Hg}}\right)$ is extremely small compared to these other extinction losses. Further, if $\alpha_{\mathrm{BG}}$ and $\alpha_{M}$ are not perfectly stable in time, differential on-line/offline tuning following a $10 \mathrm{~s}$ measurement time may not be fully accurate.

As mentioned in Sect. 4.2, measurements of CRDS absorption losses in laboratory-supplied air were adjusted by a baseline value when the cavity was filled with $\mathrm{Hg}^{0}$-free air (determined once per day). Although these adjustments were very small and similar to each other (i.e., $0.99 \pm 0.19 \mathrm{Mm}^{-1}$ ), we observed some differences in $\mathrm{Hg}^{0}$ free cell absorption values. Wavelength scans performed during ambient air measurements also indicated that background absorption losses were variable in time and needed to be accounted at high temporal frequency. Such variability indicated the presence of possible low-level interferences (e.g., by etalon effects, or others) contributing to observed CRDS absorption fluctuations. Other instrument characteristics such as unstable laser power, instability of the PMT, and ring-down signal analysis fitting procedures also may contribute to instrument noise and limit current instrument sensitivity. We currently are working on implementation of a fully automated "online/offline" switching procedure on a pulseto-pulse basis (i.e., at $50 \mathrm{~Hz}$ ) using a custom piezo controller, allowing for a differential measurement at a time resolution of $25 \mathrm{~Hz}$, which also will adjust continuously for system extinction losses other than $\mathrm{Hg}^{0}$. Such high-frequency tuning is critical for accurate and continuous adjustment of variable system background extinction losses and will greatly help detection limits and sensitivity of the sensor at low, ambient and sub-ambient $\mathrm{Hg}^{0}$ concentrations. Further, use of mirrors with a reflectivity higher than that of our current mirrors 
(i.e., reflectivity of $99.895 \%$ ) would reduce the influence of most issues discussed above. Such improvements in mirror reflectivity will lead to direct improvement in system detection limits and sensitivity by effectively reducing mirror extinction losses and extending absorption pathlengths according to Eqs. (6) and (7).

\section{Conclusions and future developments}

A laboratory CRDS system with greatly improved sensitivity and capabilities for the fast-response, sensitive detection of atmospheric mercury has been demonstrated and discussed. Table 1 summarizes detection limits extrapolated to $1 \mathrm{~Hz}$ of our CRDS system, previous CRDS and LIF spectrometers, and analyzer Tekran 2537B and Lumex RA-915+. Current instrument performance shows similar sensitivity and detection limit to the frequently used Tekran analyzer 2537B, albeit at higher time resolutions. Our CRDS laboratory prototype shows that measured $\mathrm{Hg}^{0}$ absorption is highly linearly related to $\mathrm{Hg}^{0}$ concentrations detected by Tekran 2537B analyzer across an $\mathrm{Hg}^{0}$ concentration range of four orders of magnitude, from $0.2 \mathrm{ng} \mathrm{m}^{-3}$ to $573 \mathrm{ng} \mathrm{m}^{-3}$. Ambient air measurements show strong absorption interferences of ozone and fine PM, which can be accounted for either by filtering or corresponding measurements of these constituents, or by differential online/offline wavelength tuning to account for their absorptions which are constant across a broad wavelength next to the narrow $\mathrm{Hg}^{0}$ absorption band. Ambient and sub-ambient $\mathrm{Hg}^{0}$ can be detected by our current prototype sensor, but variability and uncertainties exist at such low concentrations-possibly due to instability of our CRDS or laser system, unstable permeation or ambient $\mathrm{Hg}^{0}$ concentrations, or other instabilities or interferences. Another remaining challenge is to better reconcile theoretical calculations of $\mathrm{Hg}^{0}$ concentrations using reported and modeled $\mathrm{Hg}^{0}$ absorption cross sections with concentrations measured using a Tekran 2537 mercury sensor. This issue, however, could be avoided by direct cross-calibration of our CRDS system with a Tekran analyzer 2537B.

With an experimental sensitivity of $0.10 \mathrm{ng} \mathrm{m}^{-3}$ at a $10 \mathrm{~s}$ time resolution, our prototype may evolve into a real-time sensor for atmospheric gaseous elemental mercury. Notable improvements to the instrument performance currently underway include (i) automatic pulse-to-pulse tuning for differential "online/offline" wavelength measurements using a custom piezo controller; (ii) automated wavelength locking to the peak $\mathrm{Hg}^{0}$ absorption spectrum using our low-pressure mercury cell; (iii) integration of the sensor into a mobile rack and fiber coupling of the laser signal into the cavity for easy field deployment of the system; and (iv) development and use of higher reflectivity mirrors to further advance sensitivity of CRDS measurements.
Acknowledgements. This research has been funded by the NSF EPSCoR program, the NSF Major Research Instrumentation Program (grant \#0923485), and a Lavoisier fellowship from the French Ministry of Foreign Affairs. We thank Rishi Parashar for help in $\mathrm{C}^{++}$programming, Rick Purcell for help in development of the $\mathrm{Hg}^{0}$ vapor generation system, Martin Scheid for sharing information about his previous measurements of $\mathrm{Hg}^{0}$ absorption spectrum, Gouxun Tian for his help with Labview software development, Barbara Zielinska and Anna Cunningham for supply of an ozone denuder, and Azer Yalin for providing an initial version of the code used for $\mathrm{Hg}^{0}$ absorption line modeling. We are grateful to $\mathrm{R}$. Kreidberg for providing help in editing the manuscript.

Edited by: K.-H. Kim

\section{References}

Anderson, T. N., Magnuson, J. K., and Lucht, R. P.: Diode-laserbased sensor for ultraviolet absorption measurements of atomic mercury, Appl. Phys. B-Lasers O., 87(2), 341-353, 2007.

ASTM: Standard Practice for Preparation and Use of an Ice-Point Bath as a Reference Temperature, E563-082008, 2008.

Bauer, D., D'Ottone, L., Campuzano-Jost, P., and Hynes, A. J.: Gas phase elemental mercury: a comparison of LIF detection techniques and study of the kinetics of reaction with the hydroxyl radical, J. Photoch. Photobio. A, 157, 247-256, 2003.

Berden, G., Peeters, R., and Meijer, G.: Cavity ring-down spectroscopy: Experimental schemes and applications, Int. Rev. Phys. Chem., 19(4), 565-607, 2000.

Carruthers, A. E., Lake, T. K., Shah, A., Allen, J. W., Sibbett, W., and Dholakia, K.: Single-scan spectroscopy of mercury at $253.7 \mathrm{~nm}$ by sum frequency mixing of violet and red microlensed diode lasers, Opt. Commun., 255(4-6), 261-266, 2005.

Carter, C. C.: A Cavity Ring-Down Spectroscopy mercury continuous emission monitor, sensor research and development corporation, Orono, Maine 04473, 118 pp., 2004.

Daly, E. J., Williamson, G. I., Rusbridge, M. G., and Jacobson, A. R.: The boxcar method for the analysis of non-gaussian random signals, Plasma Phys. Contr. F., 27(7), 761-775, 1985.

Duan, Y. X., Wang, C. J., Scherrer, S. T., and Winstead, C. B.: Development of alternative plasma sources for cavity ring-down measurements of mercury, Anal. Chem., 77(15), 4883-4889, 2005.

Ebinghaus, R., Jennings, S. G., Schroeder, W. H., Berg, T., Donaghy, T., Guentzel, J., Kenny, C., Kock, H. H., Kvietkus, K., Landing, W., Muhleck, T., Munthe, J., Prestbo, E. M., Schneeberger, D., Slemr, F., Sommar, J., Urba, A., Wallschlager, D., and Xiao, Z.: International field intercomparison measurements of atmospheric mercury species at Mace Head, Ireland, Atmos. Environ., 33(18), 3063-3073, 1999.

Edner, H., Faris, G. W., Sunesson, A., and Svanberg, S.: Atmospheric atomic mercury monitoring using differential absorption lidar techniques, Appl. Optics, 28(5), p. 921, 1989.

Finkelstein, N.: An ultraviolet laser source and spectral imaging filters for non-intrusive laser-based diagnositc, $\mathrm{Ph} . \mathrm{D}$. thesis, Princeton University - Mechanical and aerospace engineering, 232 pp., 1998.

Frohlich, C. and Shaw, G. E.: New determination of Rayleighscattering in the terrestrial atmosphere, Appl. Optics, 19(11) 
1773-1775, 1980.

Jongma, R. T., Boogaarts, M. G. H., Holleman, I., and Meijer, G.: Trace gas-detection with Cavity Ring Down Spectroscopy, Rev. Sci. Instrum., 66(4), 2821-2828, 1995.

Kim, K. H., Mishra, V. K., and Hong, S.-M.: The rapid and continuous analysis of mercury behavior in ambient air, Atmos. Environ., 40(18), 3281-3293, 2006.

Molina, L. T. and Molina, M. J.: Absolute absorption cross sections of ozone in the 185 to $350-\mathrm{nm}$ wavelength range, J. Geophys. Res., 91, 14501-14508, 1986.

Moosmüller, H., Varma, R., and Arnott, W. P.: Cavity Ring-Down and Cavity-Enhanced Detection techniques for the measurement of aerosol extinction, Aerosol Sci. Technol., 39, 30-39, 2005.

O'Keefe, A. and Deacon, D. A. G.: Cavity Ring-Down optical spectrometer for absorption-measurements using pulsed laser sources, Rev. Sci. Instrum., 59(12), 2544-2551, 1988.

Obrist, D., Hallar, A. G., McCubbin, I., Stephens, B. B., and Rahn, T.: Atmospheric mercury concentrations at Storm Peak Laboratory in the Rocky Mountains: Evidence for long-range transport from Asia, boundary layer contributions, and plant mercury uptake, Atmos. Environ., 42(33), 7579-7589, 2008.

Ramponi, A. J., Milanovich, F. P., Kan, T., and Deacon, D.: Highsensitivity atmospheric transmission measurements using a Cavity Ringdown technique, Appl. Optics, 27(22), 4606-4608, 1988.

Scheid, M., Markert, F., Walz, J., Wang, J. Y., Kirchner, M., and Hansch, T. W.: $750 \mathrm{~mW}$ continuous-wave solid-state deep ultraviolet laser source at the $253.7 \mathrm{~nm}$ transition in mercury, Opt. Lett., 32(8), 955-957, 2007.
Schroeder, W. H., Keeler, G., Kock, H., Roussel, P., Schneeberger, D., and Schaedlich, F.: International field intercomparison of atmospheric mercury measurement methods, Water Air Soil Poll., 80, 611-620, 1995.

Schroeder, W. H. and Munthe, J.: Atmospheric mercury - An overview, Atmos. Environ., 32(5), 809-822, 1998.

Spuler, S., Linne, M., Sappey, A., and Snyder, S.: Development of a cavity ringdown laser absorption spectrometer for detection of trace levels of mercury, Appl. Optics, 39, 2480-2486, 2000.

Stanford Research Systems: Application Note \#4: photon counting, lock-in detection, or Boxcar averaging, Sunnyvale, CA, 2001.

Tao, S. Q., Mazzotti, F. J., Winstead, C. B., and Miller, G. P.: Determination of elemental mercury by cavity ringdown spectrometry, Analyst, 125(6), 1021-1023, 2000.

Tian, G., Moosmüller, H., and Arnott, W. P.: Simultaneous photoacoustic spectroscopy of aerosol and oxygen A-band absorption for the calibration of aerosol light absorption measurements, Aerosol Sci. Technol., 43, 1084-1090, 2009.

Valente, R. J., Shea, C., Humes, K. L., and Tanner, R. L.: Atmospheric mercury in the Great Smoky Mountains compared to regional and global levels, Atmos. Environ., 41(9), 1861-1873, 2007.

Wang, C. J., Scherrer, S. T., Duan, Y. X., and Winstead, C. B.: Cavity ringdown measurements of mercury and its hyperfine structures at $254 \mathrm{~nm}$ in an atmospheric microwave plasma: spectral interference and analytical performance, J. Anal. Atom. Spectrom., 20(7), 638-644, 2005. 